\title{
COMPARISON OF SELECTED RISK FACTORS IN CARDIOVASCULAR DISEASES IN TWO DIFFERENT POPULATIONS OF THE CZECH REPUBLIC
}

\author{
Vladimír Pavlík', Václav Šafka1, Lucie Pravdová1, Miroslav Urban", ${ }^{1}$, Petr Lašák', Milan Tuček ${ }^{3}$ \\ ${ }^{1}$ Department of Military Internal Medicine and Military Hygiene, Faculty of Military Health Sciences, University of Defence, Hradec Králové, \\ Czech Republic \\ ${ }^{2}$ Centre of Occupational Health, National Institute of Public Health, Prague, Czech Republic \\ ${ }^{3}$ Institute of Hygiene and Epidemiology, First Faculty of Medicine, Charles University, Prague, Czech Republic
}

\begin{abstract}
SUMMARY
Objectives: The aim of this work is to compare the current prevalence of selected risk factors in cardiovascular diseases in the Czech general population in a particular region with a selected population of Czech soldiers in a particular military unit.

Methods: Within medical preventive examinations, data from 684 civilians aged between 30-60 years were obtained (405 men and 279 women). Within compulsory medical preventive examinations, data from 659 soldiers from a particular military unit aged between 30-60 years were obtained (576 men and 83 women). Anthropometric parameters such as height and body weight were monitored and then used to calculate the values of Body Mass Index (BMI) and waist circumference. From biochemical parameters the following values were monitored: glycaemia, uric acid, total cholesterol, LDL-cholesterol, HDL-cholesterol, triglycerides, ALT, and GGT. As for the demographic data, age and gender were processed. In the cohort of male soldiers a questionnaire was used to find the extent of cigarette smoking, frequency of using alcoholic drinks and performance of regular physical activities such as aerobic exercises.

Results: As for cardiovascular risk, assessed anthropometric parameters in monitored female age categories are statistically significantly lower $(p<0.05)$ in women in the Army of the Czech Republic (ACR) compared to the female civilian population. Most of the biochemical parameters also display values that indicate the female military population is healthier than the civilian in these parameters. On the other hand, assessed anthropometric parameters in monitored male age categories are statistically significantly lower $(p<0.001)$ in civilian men compared to the male military population. Most of the assessed biochemical parameters show statistically significant health-indicative values in the male civilian population as well.

Conclusion: This work revealed differences in anthropometric and biochemical parameters between the examined civilian and military populations. As for cardiovascular risk, the main findings are significantly worse anthropometric and biochemical parameters in the selected male military cohort compared to the male civilian cohort.
\end{abstract}

Key words: cardiovascular disease, obesity, population, anthropometry, preventive measures

Address for correspondence: V. Pavlík, Department of Military Internal Medicine and Military Hygiene, Faculty of Military Health Sciences, University of Defence, Třebešská 1575, 50001 Hradec Králové, Czech Republic. E-mail: vladimir.pavlik@unob.cz

https://doi.org/10.21101/cejph.a6182

\section{INTRODUCTION}

Cardiovascular diseases (CVD), particularly ischaemic heart disease, is the number one cause in total morbidity and mortality in the Czech Republic. Ischaemic heart disease results in approximately $40 \%$ of all deaths due to cardiovascular causes (1). Increased concentrations of total cholesterol and LDL-cholesterol in plasma, decreased concentrations of HDL-cholesterol, arterial hypertension, cigarette smoking, diabetes mellitus, and obesity are considered causal risk factors of CVD (1). According to the BMI value, more than $55 \%$ of inhabitants in the Czech Republic suffer from being overweight and/or obese (2). This work compares the prevalence of selected risk factors in a sample of the Czech general population, obtained within our previous research (3), with the military population of a selected elite unit of the Army of the Czech Republic (ACR).

\section{MATERIALS AND METHODS}

The cohort of civilian patients was recruited consecutively and non-selectively within voluntary medical preventive examinations, which were performed in several general practitioners' surgeries in the administrative region of the capital city of Prague from 2016 to 2018, without any exclusion criteria except for age to meet the age structure of the military cohort. The cohort of military professionals was recruited within compulsory extended medical examinations in one elite unit of the ACR in 2017 , but this cohort was given an extra questionnaire to obtain the behavioural data.

In the above-mentioned groups, anthropometric parameters such as height, body weight, values of body mass index (BMI) and waist circumference were monitored. The body weight and waist circumference were determined in each proband wearing 
only underwear and without shoes under standard conditions, meaning on an empty stomach in the morning. To determine the body weight, standard stand-on scales were used. The height measurement was performed using an altimeter, the measured person was always without shoes. BMI was calculated as the ratio of body weight in $\mathrm{kg}$ and height in meters squared (4). The waist circumference was measured at half-distance between the lowest rib and iliac crest at a horizontal level. Waist circumference values are defined according to cardiometabolic risk. There is a moderate risk with waist circumference $>94 \mathrm{~cm}$ in men and $80 \mathrm{~cm}$ in women (risk level 1), and a high risk (risk level 2) with waist circumference higher than $102 \mathrm{~cm}$ in men and $88 \mathrm{~cm}$ in women (5). From physical parameters, blood pressure and heart rate were measured.

From biochemical parameters, the following values were monitored: glycaemia, uric acid, total cholesterol, LDLcholesterol, HDL-cholesterol, triglycerides, ALT, and GGT. A venous blood sample was withdrawn on an empty stomach and parameters were determined in certified laboratories using standard laboratory methods. Demographic data such as age and gender were processed.

In the cohort of male soldiers a questionnaire was used to analyse behavioural risk factors such as cigarette smoking and alcohol consumption, and to find their attitude towards regular physical activity (aerobic exercises). These data were categorized according to their characteristics and intensity as follows: cigarette smoking - smoking intensity, i.e. the number of cigarettes a day (4 categories) and smoking duration ( 3 categories) were evaluated; alcohol consumption - the kind of alcoholic drinks ( 3 categories) and average alcohol consumption a day (4 categories) were evaluated; physical activity - daily duration of physical activity (6 categories) and weekly frequency of physical activity (5 categories) were evaluated. For each modality the above-mentioned categories were united into one reflecting the total organism load caused by the relevant activity.
The statistical data analysis was carried out using the software of IBM ${ }^{\circledR}$ SPSS $^{\circledR}$ statistics, Version 25. The comparison of cohorts was performed using a Student's t-test. The significance level was determined in all analyses as $p<0.05$. The correlation analysis was performed using the Pearson's correlation coefficient and the significance level was also determined as $p<0.05$. The data of the cohort of male soldiers over the age of 50 were included in this correlation analysis.

\section{RESULTS}

From 2017 to 2018 the data from 684 civilians aged between 30-60 years (405 men and 279 women) were systematically obtained within medical preventive examinations. The average age of the examined civilian cohort was 45.5 years $(\mathrm{SD}=8.9)$ in men and 46.1 years (SD = 7.7) in women. In 2017 the data from 659 soldiers aged between 30-60 years serving in one particular military unit (576 men and 83 women) were obtained within compulsory extended medical examinations. The average age of the examined military cohort was 43.8 years $(\mathrm{SD}=5.4)$ in men and 45.0 years $(\mathrm{SD}=5.3)$ in women.

For more accurate evaluation and comparison of both the examined cohorts, individuals were divided into age categories as follows: up to the age of 40 years, up to the age of 50 years and up to the age of 60 years. Due to disparity in the number of men and women in the oldest age category, attention was aimed at the age categories up to the age of 40 years and up to the age of 50 years. To get a similar age structure, only probands aged between 34-40 years were included in the civilian cohort up to the age of 40 years, because the military cohort did not have any probands aged between 30-33 years. Assessed anthropometric parameters in monitored female age categories are statistically significantly lower $(\mathrm{p}<0.05)$ in female military professionals compared to the female civilian population (Table 1). Biochemical

Table 1. Anthropometric and physical examination - comparison of cohorts

\begin{tabular}{|c|c|c|c|c|c|c|}
\hline \multirow{2}{*}{ Parameter } & \multicolumn{3}{|c|}{ Females - mean (SD) } & \multicolumn{3}{|c|}{ Males - mean (SD) } \\
\hline & Army & Civil & $p$ (t-test) & Army & Civil & $p$ (t-test) \\
\hline Age $34-40$ years & $\mathrm{n}=\mathbf{2 0}$ & $\mathrm{n}=87$ & & $n=152$ & $\mathrm{n}=87$ & \\
\hline BMI $\left(\mathrm{kg} / \mathrm{m}^{2}\right)$ & $23.9(3.1)$ & $27.0(3.9)$ & 0.001 & $27.1(3.0)$ & $24.1(4.3)$ & $<0.001$ \\
\hline Waist (cm) & $76.7(6.3)$ & $95.8(13.0)$ & $<0.001$ & $91.2(9.9)$ & $82.6(13.9)$ & $<0.001$ \\
\hline $\mathrm{BPs}(\mathrm{mmHg})$ & $118.0(11.0)$ & $128.0(12.5)$ & 0.001 & $126.2(10.8)$ & $119.7(14.9)$ & 0.001 \\
\hline $\mathrm{BPd}(\mathrm{mmHg})$ & $74.2(7.9)$ & $78.5(10.2)$ & 0.078 & $78.8(7.5)$ & $73.3(9.4)$ & $<0.001$ \\
\hline $\operatorname{HR}\left(\min ^{-1}\right)$ & $76.9(12.0)$ & $76.6(14.9)$ & 0.939 & $73.3(10.8)$ & $77.8(10.8)$ & 0.002 \\
\hline Age $41-50$ years & $n=47$ & $n=104$ & & $\mathrm{n}=353$ & $n=131$ & \\
\hline $\mathrm{BMI}\left(\mathrm{kg} / \mathrm{m}^{2}\right)$ & $24.7(4.4)$ & $27.7(3.9)$ & $<0.001$ & $27.7(3.3)$ & $25.2(4.9)$ & $<0.001$ \\
\hline Waist (cm) & $77.4(10.7)$ & $97.8(14.4)$ & $<0.001$ & $93.6(9.5)$ & $84.1(16.2)$ & $<0.001$ \\
\hline $\mathrm{BPs}(\mathrm{mmHg})$ & $117.4(10.1)$ & $131.6(13.0)$ & $<0.001$ & $125.8(10.8)$ & $119.1(16.4)$ & $<0.001$ \\
\hline $\mathrm{BPd}(\mathrm{mmHg})$ & $74.5(6.9)$ & $82.2(10.0)$ & $<0.001$ & $78.8(7.6)$ & $74.1(11.1)$ & $<0.001$ \\
\hline $\operatorname{HR}\left(\min ^{-1}\right)$ & $74.8(13.4)$ & $74.7(12.6)$ & 0.956 & $73.5(11.5)$ & $76.5(11.7)$ & 0.011 \\
\hline
\end{tabular}

$\mathrm{n}$ - number of subjects; SD - standard deviation; BMI - body mass index; waist - waist circumference; BPs - systolic blood pressure; BPd - diastolic blood pressure; HR - heart rate 
parameters also show health-indicative values in the female military population. These biochemical parameters statistically significantly differ for example in the values of liver blood tests and lipid spectrum, with the exception of total cholesterol and uric acid (Table 2).

On the other hand, assessed anthropometric parameters in monitored male age categories were statistically significantly lower $(\mathrm{p}<0.001)$ in the male civilian population compared to the male military population (Table 1). Unlike the female population, in the male population numerically closer cohorts were compared. Most of the assessed biochemical parameters also showed health-indicative values with a statistically significant difference in the male civilian population (Table 2).

Heart rates in women were in both the populations almost the same, whereas heart rates in men were statistically significantly lower in the military population (Table 1).

To explain statistically significantly worse anthropometric and biochemical parameters in the male military population compared to the male civilian population, a correlation analysis of not only selected anthropometric and behavioural parameters (Table 3), but also of selected biochemical and anthropometric parameters and regimental habits in male military professionals was performed (Table 4).

An increase in abdominal obesity depending on age was found, but the association between age and regimental habits was not proved. The BMI value correlates closely with waist circumference value and predicts worse prognostic biochemical parameters (glycaemia, liver blood tests, lipid profile). An association between BMI value and cigarette smoking or alcohol consumption was not proved, but weak negative correlations of BMI and waist circumference with physical activity were discovered (Table 3).

From biochemical parameters, age influences only glycaemia values. Increasing age does not influence any other biochemical parameters. Almost all assessed biochemical indicators of

Table 3. Correlation of behavioural activities with body parameters

\begin{tabular}{|c|c|c|c|c|c|c|}
\hline \multicolumn{2}{|c|}{} & $\begin{array}{c}\text { BMI } \\
n=576\end{array}$ & $\begin{array}{c}\text { Waist } \\
n=576\end{array}$ & $\begin{array}{c}\text { Smoking } \\
n=576\end{array}$ & $\begin{array}{c}\text { Alcohol } \\
n=576\end{array}$ & $\begin{array}{c}\text { Activity } \\
n=323\end{array}$ \\
\hline \multirow{2}{*}{ Age } & $\mathbf{r}$ (Pearson) & 0.128 & 0.159 & 0.025 & 0.005 & 0.031 \\
\cline { 2 - 7 } & $p$-value & 0.002 & $<0.001$ & 0.545 & 0.903 & 0.575 \\
\hline \multirow{2}{*}{ BMI } & $\mathbf{r}$ (Pearson) & & 0.812 & 0.021 & 0.036 & -0.110 \\
\cline { 2 - 7 } & $p$-value & & $<0.001$ & 0.610 & 0.388 & 0.048 \\
\hline \multirow{2}{*}{ Waist } & $\mathbf{r}$ (Pearson) & & & 0.078 & 0.042 & -0.128 \\
\cline { 2 - 7 } & p-value & & & 0.062 & 0.312 & 0.022 \\
\hline
\end{tabular}

$\mathrm{n}$ - number of subjects; BMI - body mass index; waist - waist circumference; smoking - active smoking quantified in categories; alcohol - consumption

of alcohol quantified in categories; activity - physical aerobic activity quantified in categories

Table 2. Laboratory serum biochemical values - comparison of cohorts

\begin{tabular}{|c|c|c|c|c|c|c|}
\hline \multirow{2}{*}{ Parameter } & \multicolumn{3}{|c|}{ Females - mean (SD) } & \multicolumn{3}{|c|}{ Males - mean (SD) } \\
\hline & Army & Civil & $p$ (t-test) & Army & Civil & $p$ (t-test) \\
\hline Age $34-40$ years & $n=20$ & $n=87$ & & $n=152$ & $n=87$ & \\
\hline glc (mmol/l) & $4.66(0.35)$ & $4.90(0.55)$ & 0.020 & $4.64(0.49)$ & $4.85(0.58)$ & 0.004 \\
\hline $\operatorname{ALT}(\mu k a t / l)$ & $0.35(0.18)$ & $0.58(0.37)$ & 0.008 & $0.68(0.37)$ & $0.38(0.13)$ & $<0.001$ \\
\hline GGT ( $\mu k a t / l)$ & $0.39(0.32)$ & $0.59(0.50)$ & 0.084 & $0.90(1.28)$ & $0.43(0.26)$ & 0.001 \\
\hline urate $(\mu \mathrm{mol} / \mathrm{l})$ & $267(61)$ & $324(99)$ & 0.002 & $381(71)$ & $271(72)$ & $<0.001$ \\
\hline chol. (mmol/l) & $4.95(0.81)$ & $5.21(0.93)$ & 0.259 & $5.45(0.97)$ & $4.87(0.86)$ & $<0.001$ \\
\hline TAG (mmol/l) & $1.03(0.39)$ & $1.47(0.80)$ & 0.001 & $1.58(1.26)$ & $1.12(0.57)$ & $<0.001$ \\
\hline $\mathrm{HDL}(\mathrm{mmol} / \mathrm{l})$ & $1.44(0.25)$ & $1.33(0.33)$ & 0.168 & $1.19(0.25)$ & $1.47(0.43)$ & $<0.001$ \\
\hline LDL (mmol/l) & $2.16(0.84)$ & $3.15(0.74)$ & $<0.001$ & $2.85(0.73)$ & $2.76(0.63)$ & 0.359 \\
\hline Age $41-50$ years & $n=47$ & $\mathrm{n}=104$ & & $\mathrm{n}=353$ & $n=131$ & \\
\hline glc (mmol/l) & $4.50(0.39)$ & $5.10(0.61)$ & $<0.001$ & $4.80(0.59)$ & $4.96(0.56)$ & 0.007 \\
\hline ALT ( $\mu$ kat/l) & $0.33(0.12)$ & $0.60(0.34)$ & $<0.001$ & $0.61(0.30)$ & $0.42(0.19)$ & $<0.001$ \\
\hline GGT ( $\mu k a t / l)$ & $0.31(0.14)$ & $0.79(1.25)$ & $<0.001$ & $0.73(0.71)$ & $0.51(0.35)$ & $<0.001$ \\
\hline urate $(\mu \mathrm{mol} / \mathrm{l})$ & $264(61)$ & 331 (95) & $<0.001$ & 376 (72) & $262(73)$ & $<0.001$ \\
\hline chol. (mmol/l) & $5.40(0.94)$ & $5.26(0.87)$ & 0.367 & $5.67(1.00)$ & $5.07(0.89)$ & $<0.001$ \\
\hline TAG (mmol/l) & $0.95(0.4)$ & $1.59(0.96)$ & $<0.001$ & $1.60(1.00)$ & $1.29(0.58)$ & $<0.001$ \\
\hline $\mathrm{HDL}(\mathrm{mmol} / \mathrm{l})$ & $1.49(0.32)$ & $1.41(0.41)$ & 0.230 & $1.21(0.28)$ & $1.49(0.45)$ & $<0.001$ \\
\hline LDL (mmol/l) & $2.64(0.67)$ & $3.09(0.62)$ & $<0.001$ & $2.99(0.78)$ & $2.86(0.73)$ & 0.086 \\
\hline
\end{tabular}

$\mathrm{n}$ - number of subjects; SD - standard deviation; glc - glycaemia, ALT - alanine aminotransferase; GGT - gamma-glutamyltransferase; urate - uric acid; chol. - total cholesterol; TAG - triglycerides; HDL - HDL-cholesterol; LDL - LDL-cholesterol 
Table 4. Correlation of some serum biochemical parameters with body parameters and smoking $(n=576)$

\begin{tabular}{|c|c|c|c|c|c|c|c|c|c|}
\hline & & glc & ALT & GGT & urate & chol. & TAG & HDL & LDL \\
\hline \multirow{2}{*}{ Age } & $\mathbf{r}$ (Pearson) & 0.266 & -0.083 & -0.069 & -0.085 & 0.064 & -0.024 & 0.033 & 0.059 \\
\hline & $p$-value & $<0.001$ & 0.047 & 0.097 & 0.042 & 0.124 & 0.563 & 0.430 & 0.156 \\
\hline \multirow{2}{*}{ BMI } & $\mathbf{r}$ (Pearson) & 0.207 & 0.324 & 0.236 & 0.261 & 0.069 & 0.247 & -0.289 & 0.069 \\
\hline & $p$-value & $<0.001$ & $<0.001$ & $<0.001$ & $<0.001$ & 0.096 & $<0.001$ & $<0.001$ & 0.099 \\
\hline \multirow{2}{*}{ Waist } & $\mathbf{r}$ (Pearson) & 0.253 & 0.296 & 0.218 & 0.260 & 0.060 & 0.230 & -0.249 & 0.051 \\
\hline & $p$-value & $<0.001$ & $<0.001$ & $<0.001$ & $<0.001$ & 0.147 & $<0.001$ & $<0.001$ & 0.225 \\
\hline \multirow{2}{*}{ Smoking } & $\mathbf{r}$ (Pearson) & 0.072 & 0.016 & 0.093 & 0.064 & 0.067 & 0.180 & -0.104 & -0.008 \\
\hline & $p$-value & 0.082 & 0.699 & 0.025 & 0.125 & 0.111 & $<0.001$ & 0.012 & 0.854 \\
\hline
\end{tabular}

$\mathrm{n}$ - number of subjects; glc - glycaemia, ALT - alanine aminotransferase; GGT - gamma-glutamyltransferase; urate - uric acid; chol. - total cholesterol; TAG - triglycerides; HDL - HDL-cholesterol; LDL - LDL-cholesterol; BMI - body mass index; waist - waist circumference; smoking - active smoking quantified in categories

cardiovascular risk have a significant positive correlation with BMI and waist circumference values. A statistically insignificant correlation was found between cigarette smoking and some lipid profile values and GGT (Table 4).

\section{DISCUSSION}

Comparison of two different female populations in age categories 34-40 years and 41-50 years showed significantly better results in the cohort of female military professionals. The average values of BMI and waist circumference were up to standard in the female military population. On the other hand, anthropometric values in the female civilian population reached on average the values of being overweight. Health-indicative values of all assessed biochemical parameters (mostly with a statistical significance of $p<0.05)$ in both the age categories of female military professionals promise a decreased risk in incidence of cardiovascular diseases in the female military population compared to the female civilian population. A disadvantage of this comparison is the unequal number of examined women; in the age category up to the age of 40 years the number of female military professionals was 20 and the number of female civilians was 87 , in the age category up to the age of 50 the number of female military professionals was 47 and the number of female civilians was 104 . The reason is the lower number of women in the ACR in 2018 (12\% of the military population) (6).

Comparison of two different male populations in age categories 34-40 years and 41-50 years showed surprisingly significantly better results in the male civilian cohort. The observed better results can be influenced by particular selectiveness of the examined male civilian population because preventive medical examinations are for this population voluntary. It is assumed that the individuals who participate in these examinations are mostly those who care for their health status and who are interested in recommended preventive measures. This assumption can be confirmed by average values of BMI and waist circumference which were up to standard in this male civilian population. On the contrary, these values in the non-selected male military population reached on average the values of being overweight. Health-indicative values of most of the assessed biochemical parameters with a statistical significance of $p<0.05$ in both the age categories of male civilians promise a decreased risk in incidence of cardiovascular diseases in the male civilian cohort compared to the male military cohort. The number of individuals in male age categories is more comparable than in female age categories.

As expected and in accord with the results of other authors (7-9), in the monitored sample of the male military population the values of anthropometric parameters in obesity increase depending on the age of examined individuals. It seems to be partly a trend between separate age categories, and partly a result of statistically significant correlation in the male military population.

In the ACR there is, according to the previous observation, a lower number of male soldiers with the BMI values over $30 \mathrm{~kg} / \mathrm{m}^{2}$. According to the last observation in 2015, 17\% of men are diagnosed as obese. On the other hand, more than $58 \%$ of male soldiers are categorized as overweight (7). Higher values of BMI in male soldiers can be partly explained by the fact that some of these individuals have higher body weight and BMI value as a result of higher muscle mass $(7,8)$. The same results were found in the military populations of other armies $(10,11)$. In our monitored military population, a very strong correlation between BMI and waist circumference was registered and that generally indicates a prevalence of abdominal obesity. Waist circumference values are significantly lower in our civilian cohort. This reflects the selectiveness of the male civilian population which attends preventive medical examinations and is interested in further preventive and health-regimen measures.

The only health-indicative parameter that could present a higher physical fitness in our male military population and that was registered within our observation was a statistically significantly lower heart rate (Table 1).

The worse results of anthropometric and biochemical parameters in male soldiers could be explained as follows: in general, in the army the number of professions which require a long-term theoretical preparation to reach a specialty and a sedentary job is increasing. In the ACR a system of health classification was introduced. A competent military general practitioner decides on the basis of a medical examination which medical fitness category for performing active military duty each soldier meets. A considerable percentage of soldiers have a lowered health classification (category $\mathrm{C}$ ), meaning that they can perform 
active duty in the ACR but with some limitations. The reason for such a lower health classification could be the diagnosis of obesity or arterial hypertension. It is a paradox that only soldiers within category A in the health classification have to pass annual compulsory physical fitness tests. No disciplinary or financial punishments are imposed on obese soldiers in category $\mathrm{C}$; indeed, they do not even have to pass relatively hard physical fitness tests twice a year. Thus, soldiers with the lower health classification do not have any motivation to improve their health status. Soldiers from the monitored unit are revered especially for their specialty, thus not so much attention is paid to their results in physical fitness tests or to the results of their medical examinations. Psychic load is dominant over physical load in the current ACR. As a result of this situation, soldiers cope with stressful situations by excess consumption of highcalorie foods, cigarette smoking or consumption of high-calorie alcoholic drinks outside of working hours. Soldiers from the examined unit of the ACR have 24-hour shifts, thus there is a higher probability of irregular food intake which is on top of that highly caloric (12).

Some soldiers consider annual compulsory basic medical examinations a necessary evil which they must undergo. Some soldiers are not interested in reaching results and therefore there is again a decreased motivation in these soldiers to improve their health status. Most of the soldiers do not even meet 4 hours of compulsory physical training a week during their working hours. There is again no punishment for them if they do not take part in these sports activities.

The growth in anthropometric parameters of obesity depending on age has been known for a long time. The riskiest period for increase in body weight is between the years of 50 to 59 , when arterial hypertension and diabetes mellitus are most frequently diagnosed (2). In our male soldiers a positive correlation between the values of BMI and waist circumference was proved, thus it can be deduced that this is predominantly central obesity accompanied with a higher amount of adipose tissue in the abdominal area. In the monitored military population the increased muscle mass, compared to the civilian population, cannot explain the higher values of BMI and waist circumference. According to some authors, the waist circumference value is a better risk indicator for incidence of cardiovascular diseases than the BMI value $(13,14)$. It is also useful to combine the BMI values and impedance techniques (15).

A very tight positive correlation between the BMI value and the circumference value was also described in the work from 2018 (3). This correlation was found to be less tight in men than in women. This fact confirmed again a greater significance of variability of muscle mass percentage in the BMI parameter in men. Considering a higher muscle mass percentage in men, and based on the observed differences in correlation between genders, it is possible to state that the BMI value is more usable for the female population, while the waist circumference value is a more significant value for men (3).

BMI and waist circumference values also significantly and negatively correlate with the monitored biochemical parameters. This fact is obviously associated with the hormonal activity of visceral fat described in the literature $(16,17)$. The values of liver blood tests are probably associated with liver steatosis. The influence of lifestyle risk factors (cigarette smoking, alcohol consumption) on anthropometric parameters was not proved. But it was confirmed that regular endurance exercises may have a positive influence on the values of anthropometric parameters, especially waist circumference. Surprisingly, intensity of physical activity itself is not associated in our cohort with the age of individuals and does not have any significant influence either on the values of lipid spectrum, or on the results of liver blood tests.

\section{CONCLUSION}

The work confirmed statistically significant differences in anthropometric and biochemical parameters between the civilian and military populations. The main finding is that anthropometric and biochemical parameters are significantly worse in the cohort of male soldiers compared to the selected male civilian population. Worse anthropometric and biochemical parameters in the monitored male military cohort are caused by a higher amount of adipose tissue and by not adhering to preventive health regimens, dietary recommendations and physical activity recommendations $(18,19)$.

\section{Acknowledgements}

The work was supported by the Ministry of Defence, Czech Republic (A long-term organization development plan No. 1011) and by the programme PROGRES Q 25/LF1, Charles University, Prague.

\section{Conflict of Interests}

None declared

\section{REFERENCES}

1. Rosolová H, Nussbaumerová B, Mayer O Jr, Cífková R, Bruthans J. Success and failure of cardiovascular disease prevention in Czech Republic over the past 30 years. Czech part of the EUROASPIRE I-IV surveys. Physiol Res. 2017 Apr 5;66 Suppl 1:S77-84.

2. Matoulek M, Svačina Š, Lajka J. The incidence of obesity and its complications in the Czech Republic. Vnitr Lek. 2010 Oct;56(10):1019-27. (In Czech.)

3. Pavlík V, Fajfrová J, Šafka V, Pravdová L, Urban M, Krutišová P, et al. Prevalence of risk factors in cardiovascular diseases in the selected population of the Czech Republic. Centr Eur J Publ Health. 2018 Jun;26(2):118-23.

4. World Health Organization. Obesity: preventing and managing the global epidemic. Report of a WHO Consultation on Obesity, Geneva, 3-5 June 1997. Geneva: WHO; 1998.

5. Alberti KGMM, Eckel RH, Grundy SM, Zimmet PZ, Cleeman JI, Donato $\mathrm{KA}$, et al. Harmonizing the metabolic syndrome: a joint interim statement of the International Diabetes Federation Task Force on Epidemiology and Prevention; National Heart, Lung and Blood Institut; American Heart Association; World Heart Federation; International Atherosclerosis Society; and International Association for the Study of Obesity. Circulation. 2009 Oct 20;120(16):1640-5

6. Ministry of Defence of the Czech Republic, State Secretary Division. Quantitative gender analysis [Internet]. Prague: Ministry of Defence of CR; 2019 [cited 2019 Jan 1]. Available from: http://www.mocr.army. cz/assets/informacni-servis/povinne-informace/1-rovne-prilezitosti/ kvantitativni-genderova-analyza-k-1--1--2019_1.pdf.

7. Fajfrová J, Pavlík V, Šafka V, Krutišová P, Z̄etocha J. Prevalence of selected risk factors of metabolic syndrom in the Armed Forces of the Czech Republic. Mil Med Sci Lett. 2017;86(2): 52-57. (In Czech.).

8. Fajfrová J, Pavlík V, Psutka J, Husarová M, Krutišová P, Fajfr M. Prevalence of overweight and obesity in professional soldiers of the Czech Army over an 11-year period. Vojnosanit Pregl. 2016 May;73(5):422-8. 
9. Ginter E, Simko V. Adult obesity at the beginning of the 21 st century: epidemiology, pathophysiology and health risk. Bratisl Lek Listy. 2008;109(5):224-30.

10. Tomczak, A, Bertrandt J, Klos A. Physical fitness and nutritional status of polish ground force unit recruits. Biol Sport. 2012 Dec;29(4):277-80.

11. Sanderson PW, Clemes SA, Biddle SJH. Prevalence and sociodemographic correlates of obesity in the British Army. Ann Hum Biol. 2014;41(3):193-200.

12. Pravdová L, Pavlík V, Fajfrová J, Šafka V, Urban M. The system of preventive and enhanced preventive medical care in the Army of the Czech Republic. Mil Med Sci Lett. 2018;87(3):134-8. (In Czech).

13. Seo DC, Choe $S$, Torabi MR. Is waist circumference $\geq 102 / 88 \mathrm{~cm}$ better than body mass index $\geq 30$ to predict hypertension and diabetes development regardless of gender, age group and race/ethnicity? Meta-analysis. Prev Med. 2017 Apr;97:100-8.

14. Parish RC, Huang J, Mansi I. Screening for the metabolic syndrome in a public care hospital clinic population: a simple measurement of waist circumference. J Investig Med. 2011;59(1):22-6.

15. Mullie P, Vansant G, Hulens M, Clarys P, Degrave E. Evaluation of body fat estimated from body mass index and impedance in Belgian male military candidates: comparing two methods for estimating body composition. Mil Med. 2008;173(3):266-70.

16. Smith SR, Lovejoy JC, Greenway F, Ryan D, deJonge L, de la Brettonne $\mathrm{J}$, et al. Contributions of total body fat, abdominal subcutaneous adipose tissue compartments, and visceral adipose tissue to the metabolic complications of obesity. Metabolism. 2001 Apr;50(4):425-35.

17. Wajchenberg BL, Giannella-Neto D, da Silva ME, Santos RF. Depotspecific hormonal characteristics of subcutaneous and visceral adipose tissue and their relation to the metabolic syndrome. Horm Metab Res. 2002;34(11-12):616-21.

18. Pavlík V, Lašák P, Horáček J, Dlouhý M. Physical activity in the Armed Forces of the Czech Republic. Int Rev Armed Forces Med Serv. 2019;92(3):24-30.

19. Pavlík V, Šafka V, Lašák P, Urban M, Pravdová L, Fajfrová J. Options of primary prevention in the Army of the Czech Republic. Hygiena. 2019;64(3):112-6. (In Czech.)

Received March 17, 2020 Accepted in revised form May 29, 2020 